\title{
Decision Making Styles: A Systematic Review of Their Associations with Parenting
}

\author{
Eugene Lee Davids ${ }^{1} \cdot$ Nicolette Vanessa Roman ${ }^{1} \cdot$ Lloyd Leach $^{2}$
}

Received: 5 April 2015/Accepted: 5 May 2015/Published online: 14 May 2015

(C) Springer International Publishing 2015

\begin{abstract}
Decision making is a task that individuals face on a daily basis. The process of making a decision differs from one person to another. The processes involved in making a decision are defined as decision making styles, which can be either adaptive or maladaptive. Children and adolescents' decision making, however, often is thought to be associated with parenting. This review examines and describes previous studies examining the associations between decision making styles and parenting approaches. It suggests that maladaptive decision making styles are the most prevalent, and that they often are associated with detrimental outcomes for children and adolescents' development. Maladaptive decision making styles also are associated with negative parenting approaches. The review reveals that western and non-western societies play an important role in shaping these associations; however, it also finds that age and gender do not play a significant role. The review highlights gaps in literature focusing on decision making and parenting, and the continents where little research has examined the associations presented. The review adds to current debates and knowledge on youth
\end{abstract}

Eugene Lee Davids

davidse.psych@gmail.com

Nicolette Vanessa Roman

nicoletteroman@gmail.com; nroman@uwc.ac.za

Lloyd Leach

lleach@uwc.ac.za

1 Child and Family Studies Programme, Department of Social Work, University of the Western Cape,

Private Bag X17, Bellville 7535, South Africa

2 Department of Sport, Recreation and Exercise Science, University of the Western Cape,

Private Bag X17, Bellville 7535, South Africa development by providing an understanding of decision making styles from an international perspective as well as from the important role that parents play.

Keywords Adolescence - Decision making - Decision making styles · Parenting · Parenting approaches . Systematic review

\section{Introduction}

For decades, developmental theorists and researchers have been concerned with cognitive development (Moshman 2011). One theorist who has been at the forefront of cognitive development has been Piaget (1972, 2006). Piaget (1972, 2006) proposed a four-phase perspective on cognitive development; namely, the sensorimotor, preoperational, concrete operations and formal operations phases (Shaffer and Kipp 2014). The fourth phase of formal operations is normally reached during adolescence, and is synonymous with abstract thinking, logical reasoning and problem-solving skills which are important in making decisions (Swartz et al. 2008).

Conceptions of cognition and thoughts during the formal operations phase view adolescent thinking as involving hypothetical alternatives and solutions considered important for adaptive decision making (Klaczynski 2005; Steinberg 2007). Adaptive decision making can be seen as a process, in which an individual or adolescent engages in thinking about all the possible hypothetical alternatives; and the abstract consequences of each alternative (Steinberg 2007). The formal operations phase in cognitive development during adolescence is different from cognitive development in childhood. As decision making and reasoning in childhood often take place in the absence of abstract thoughts and reasoning (Moshman 2011; Shaffer 
and Kipp 2014). Decision making is, therefore, of importance when considering cognition during development.

\section{Toward an Understanding of Decision Making Styles}

Decision making is routine, as there is a constant need to negotiate the best course of action for a range of situations. The process of making a decision, however, is often stressful (Bruine de Bruin et al. 2007; Janis and Mann 1977; Salo and Allwood 2011). The processes that individuals follow in making decisions often tend to differ from person to person (Galotti et al. 2006; Riaz et al. 2012; Williams and Esmail 2014). These processes or approaches are categorized as decision making styles (Janis and Mann 1977; Scott and Bruce 1995; Leykin and DeRubeis 2010). Decision making styles often differ in the manner in which individuals gather information concerning the decision that needs to be made, as well as in the way in which they consider the possible alternatives in resolving the conflicting situation to make a decision (Saidur Rahaman 2014). Styles of decision making have also been thought of as the differences that exist between individuals in how they make sense of the information gathered and the possible alternatives (Albert and Steinberg 2011; Scott and Bruce 1995).

A number of decision making styles have been identified when individuals make critical decisions (Phillips and Ogeil 2011). Janis and Mann (1977) have proposed four styles in making a decision, namely, vigilance, hypervigilance, and defensive avoidance, which is divided into procrastination and buck-passing (Brown et al. 2011; Cenkseven-Önder 2012). These styles of decision making differ based on the belief that there is sufficient time to find alternative solutions. They also differ in their approach to a thorough, independent search for alternatives. The lack of searching for alternatives could result from leaving the responsibility to others to make a decision or postponing the process of making a decision until later.

Other researchers have identified other decision making styles. Harren (1979) identified three styles, namely rational-, intuitive- and dependent-decision making styles (Tinsley et al. 2002). Scott and Bruce (1995) supplemented Harren's proposed styles by adding avoidant- and spontaneous-decision making styles (Curşeu and Schruijer 2012; Riaz et al. 2012). These decision making styles ranged from processes in which there was a thorough evaluation of the available alternatives to decision making, based purely on feelings and intuition. Additionally, these decision making styles also ranged from autonomous, independent decision making to dependent approaches. Johnson (1978) proposed styles of making decisions that were based on two elements, namely: (1) how information was gathered, and (2) how information was analyzed. This determined the four proposed decision making styles, namely, spontaneous-internal, spontaneous-external, systematic-internal and systematic-external (Hardin and Leong 2004; Tinsley et al. 2002). In addition to these decision making styles, processes of decision making also looked at fulfilling the decision making situation.

The approaches to decision making also consider maximizing and satisfying conflictual decision making situations. Simon (1956) proposed the maximizing and satisficing decision making styles (Parker et al. 2007). The satisficing style is thought to be one where an alternative is selected, which would be acceptable to satisfy the situation in which a decision needs to be made. The maximizing style, however, is one when an alternative is selected in which the alternative goes beyond only resolving the situation, but yields an even greater outcome (Parker et al. 2007). A more recent approach to decision making styles has been proposed by Leykin and DeRubeis (2010), in which nine styles were identified that covered the varied approaches to decision making in its broadest sense, namely: respected, confident, spontaneous, dependent, vigilant, avoidant, brooding, intuitive and anxious decision making. The proposed decision making styles presented by Leykin and DeRubeis (2010) take into consideration a number of the previously proposed decision making styles.

For many years, decision making research has focused primarily on decisional processes deemed normative, and often failed to consider alternative processes or approaches to decision making (Parker et al. 2007). Normative approaches to decision making are often considered as those in which a systematic process is followed in which a number of alternatives and the possible consequences are considered. These are similar to the steps proposed in Janis and Mann's vigilant decision making style (CenksevenÖnder 2012) where individuals depart from (1) considering a wide variety of alternatives as solutions; (2) considering the various aims and objectives that need to be satisfied and to considering whether they are consistent with the individual's values; (3) considering the pros and cons of each alternative; (4) researching new information that exists on the various solutions; (5) collating and making sense of all the solutions, and considering the course of action to be taken; (6) considering the pros and cons of the solutions and (7) considering a plan of action for the selected solution and the possible risks (Burnett 1991; CenksevenÖnder 2012). Decision making situations in which there is a thorough evaluation of alternatives, as presented in the seven steps above, is often thought to yield the most desirable outcomes.

A number of studies have looked at decision making styles, but mainly in the area of career decision making and development, marketing and consumer studies (such as 
Faraci et al. 2013; Madahi et al. 2012; Mokhlis and Salleh 2009). There has been a lack of focus in research on decision making styles or processes when considering individual decision making (Commendador 2011; Wolff and Crockett 2011; Galotti 2007; Parker et al. 2007; Reyna and Farley 2006; Scott and Bruce 1995). Decision making research has also missed the complexities of social phenomena. Often experimental research has largely been considered when examining decision making processes. However, this experimentation takes place within a laboratory setting where social phenomena are lacking; and it excludes therefore the real-life experience of the decision making process (Wolff and Crockett 2011). Thus, there is a variety of ways in which individuals make decisions. However, as Piaget (1972, 2006) suggests, decision making forms part of a developmental process, that really takes effect in its implementation during adolescence. Decision making during adolescence is important, as it assists with the many challenges that are common to this developmental phase (Galotti et al. 2006). There is the assumption that independent decision making styles develop during adolescence, but Özütrk et al. (2011) believe that they start during pre-adolescence, consequential to the familial environment.

\section{Parenting Approaches and the Relationship with Child and Adolescent Decision Making}

At the center of the familial environment is parenting (Wolff and Crockett 2011). A number of approaches to explain parenting and styles of parenting have been identified in the familial environment (Wood et al. 2003; Aunola and Nurmi 2005). These approaches include (1) parenting dimensions, such as behavior control, affection and psychological control (Aunola and Nurmi 2005); and (2) parenting styles, such as authoritative, authoritarian and permissive parenting, as proposed by Baumrind (1989, 1991) (Brand et al. 2009). Additionally, Maccoby and Martin (1983) proposed indulgent and neglectful parenting, in addition to the parenting styles proposed by Baumrind (Aunola and Nurmi 2005).

When examining parenting, Baumrind's (1989, 1991) typology of parenting styles is often considered. However, parenting is very complex and focusing only on parenting styles as identified by Baumrind (1989, 1991) may be considered very limiting. One important reason for this could be the role of societal norms. Previous research has found that there are contradictions in the perceptions of Baumrind's authoritative parenting (Sorkhabi 2005). Individualistic societies have viewed authoritative parenting as yielding the most desirable developmental outcomes on children and adolescents, but collectivist societies differ with this view of authoritative parenting (Chao 2001;
Sorkhabi 2005). Another consideration could be that approaches to parenting are often considered as being behaviors that parents display with regard to child rearing. This creates a certain context in which uniform behaviors are exhibited and thought to have the desired outcome on the development of children and adolescents (such as showing warmth, affection, and appropriate child monitoring and supervision) (Brand et al. 2009; Udell et al. 2008; Lee et al. 2006).

Considering the approaches to parenting as opposed to parenting styles allows one to examine the associations between decision making styles and parenting in more depth, and would greatly add to the current knowledge that exists in the field of decision making and parenting. Wolff and Crockett (2011) view the role of parents and parenting as critical in decision making, particularly when considering its influence on engagement in decision making. Parenting has been found to also nurture the development of certain decisional making styles in children and adolescents (Udell et al. 2008).

Decision making often takes place in a social context, very often the parental home of children and adolescents (Wolff and Crockett 2011). The social context often plays an important role when deciding which decision making styles to engage. Research suggests that the social context allows an individual to move between a primary and a secondary decision making style (Driver et al. 1990; Gati et al. 2010). The primary decision making style is considered as being the dominant decision making style, being the most prevalent when making decisions. Brown and Mann (1990) and Udell et al. (2008) emphasize the importance that the familial environment plays in the development of adolescent decision making abilities. In addition, the way in which adolescents develop their decision making is often based on their parents' decision making strategies (Özütrk et al. 2011). The parental home allows for engagement in decision making styles as an outcome of the beliefs, attitudes and parental approaches, and is fundamental for socialization and development (Fuemmeler et al. 2012; Putallaz et al. 1998; Vandeleur et al. 2007). Positive parental approaches in the context of child development can be seen as promoting pro-psychosocial development and adjustment (Fuemmeler et al. 2012). Negative parenting approaches, however, could hinder this development in later life (Betts et al. 2013; Whittaker and Cornthwaite 2000). Positive parenting approaches are behaviors and approaches in the parent-child relationship that involve warmth, nurturing, assistance and monitoring (Lee et al. 2006), while negative parenting approaches often involve reduced supervision and monitoring, as well as inconsistent or harsh forms of discipline (Barry et al. 2008). These approaches to parenting are also considered important in the development of child and adolescent decision making. 


\section{The Current Study}

Research focusing on decision making styles of children and adolescents has been associated with parenting (Udell et al. 2008; Fuemmeler et al. 2012). With the plethora of decision making styles and the complexity of parenting, a comprehensive review was needed to establish these associations. Therefore, the objective of this study was to systematically review and describe previous research that examined the association between decision making styles and parenting approaches. In the review, decision making styles were categorized into (1) adaptive and (2) maladaptive decision making styles, and the approaches of parenting were categorized into (1) positive and (2) negative parenting. In addition, the review aimed to recognize some of the gaps and limitations in the existing body of literature. The results presented in this review provide the foundation for future research in parenting, as well as judgment and decision making of children and adolescents. The findings presented also serve to inform parenting interventions that focus on the process of decision making rather than the behavioral outcomes.

\section{Methods}

A systematic review was conducted to establish the relationship between parenting approaches and decision making styles among children and adolescents. The terms and definitions in the context of this systematic review are defined in Table 1.

\section{Search Strategy}

A search was conducted in September 2014 using the following databases and journals: Science Direct, Ebscohost (Academic Search Complete, PsycArticles, Medline, SocIndex and ERIC), BioMed Central, PubMed, Directory of Open Access Journals (DOAJ) and SAGE Journals from January 2004 to October 2014. The review consisted of studies that examined the relationship between decision making styles and perceived parenting approaches. The terms used in the search included decision making, decision making styles, choice making styles, decision making approaches, parenting, parenting styles, parenting approaches, authoritative parenting, authoritarian parenting, permissive parenting and uninvolved parenting. Titles and abstracts of publications were examined using the inclusion criteria. The retrieval of full text articles was done by one of the reviewers and the same process was then followed by the other reviewers to determine whether the articles met the inclusion criteria.

\section{Inclusion Criteria}

The following criteria were considered for inclusion in the systematic review: the study should have (1) been published in or translated into the English language; (2) been published between 2004 and 2014; (3) used either children, adolescents or youth as part of the sample; and (4) examined the relationship or association between parenting approaches and decision making styles or processes; and (5) could be either cross-sectional or longitudinal studies.

\section{Methods of the Review}

An initial search and review of the abstracts and articles were conducted by the first author. The initial search yielded 17,632 articles for the keywords decision making and parenting. The searches thereafter yielded 36,964 articles for decision making styles, choice making styles, decision making approaches, parenting styles, parenting approaches, authoritative parenting, authoritarian parenting, permissive parenting and uninvolved parenting. Subsequent to the searches, the titles were reviewed for eligibility and a sample of 60 studies was identified. Seventeen additional studies were obtained from other sources and reference lists of other articles that produced a total of 77 articles. Next, all duplicates were removed, reducing the sample to 35 articles. These articles were independently read and assessed and 15 articles were

Table 1 Terms and definitions

\begin{tabular}{ll}
\hline Term & Definition \\
\hline Decision making & $\begin{array}{c}\text { "Process of choosing between different alternatives while in the midst of pursuing a goal" (Cenkseven-Önder 2012; Miller } \\
\text { and Byrnes 2001) }\end{array}$ \\
$\begin{array}{c}\text { Decision making } \\
\text { styles }\end{array}$ & $\begin{array}{c}\text { How individuals differ when considering alternatives in making a decision as well as the process involved in decision } \\
\text { making (Hardin and Leong 2004; Scott and Bruce 1995) }\end{array}$ \\
$\begin{array}{l}\text { Parenting } \\
\text { approaches }\end{array}$ & $\begin{array}{l}\text { Strategies or ways used by parents in the rearing and caring for their children/offspring (Kitamura et al. 2014) } \\
\end{array}$
\end{tabular}


finally selected for inclusion in the methodological quality appraisal.

\section{Methodological Quality Appraisal}

The methodological quality for the studies was assessed using an instrument (Table 2) adapted from previous systematic reviews by Louw et al. (2007), Wong et al. (2008), Roman and Frantz (2013) as well as Davids and Roman (2014). The final sample consisted of 14 articles which were included in the systematic review (Table 3 ). Figure 1 outlines the process involved in the systematic review.

\section{Data Extraction}

After the methodological quality appraisal, the studies that met the criteria for the categories of satisfactory to good were reviewed, and a data extraction table (Table 4) was drawn up, using Davids and Roman's (2014) data extraction tool. The information in the data extraction table included author, geographical location of study, study design, participant information, instruments used, decision making style, and the relationship or association between decision making styles and parenting approaches (Table 4).

\section{Results}

An outline of the studies that were considered for inclusion in the methodological appraisal phase of the systematic review can be found in Table 3. From the initial 35 studies retrieved, 15 were methodologically appraised. The criteria that had to be satisfied in the methodological quality assessment included sampling methods, measurement tool, the data sources used, whether decision making styles or processes were examined, and whether the relationship between decision making styles and parenting approaches was discussed. Of the 15 studies that formed part of the methodological appraisal, 14 scored good (67-100\%) and one had a low score (0-33\%). Thus, 14 studies were included in the final review.

\section{Overview of Reviewed Studies}

The final sample of 14 studies included in the systematic review consisted of eleven cross-sectional studies (Cheung et al. 2014; Parishani and Nilforooshan 2014; Sovet and Metz 2014; Yang et al. 2014; Michael et al. 2013; Pérez and Cumsille 2012; Commendador 2011; Koumoundourou et al. 2011; Doğan and Kazak 2010; Lease and Dahlbeck 2009; Keller and Whiston 2008) and three longitudinal

Table 2 Methodological quality appraisal tool

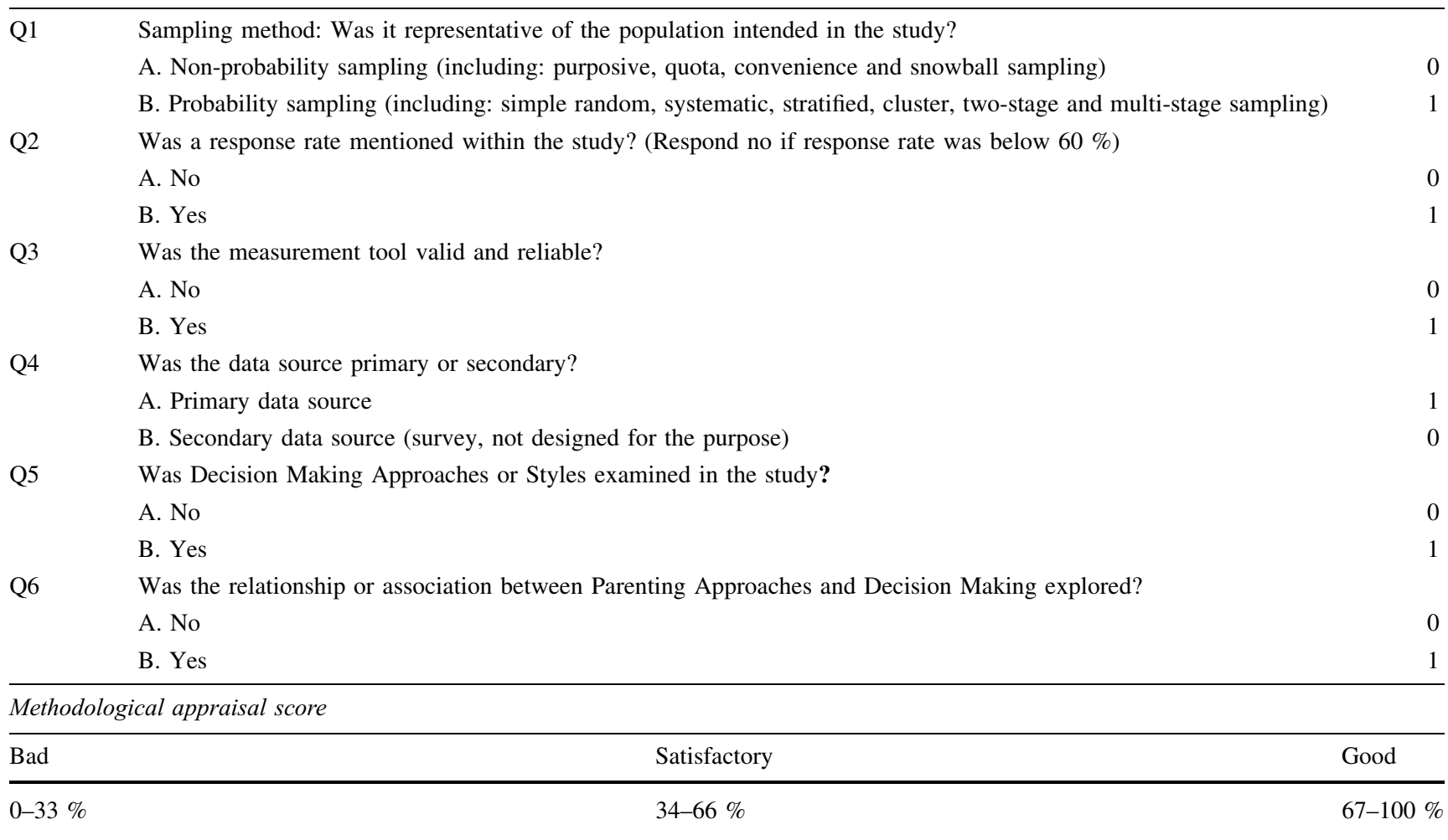

Scoring: total score divided by total number of items multiplied by 100 (expressed as a percentage) 
Table 3 Methodological appraisal

Fig. 1 Schematic representation of systematic review process

\begin{tabular}{lllllllll}
\hline Author(s) & Q1 & Q2 & Q3 & Q4 & Q5 & Q6 & $\%$ & Decision \\
\hline Cheung et al. (2014) & 0 & 0 & 1 & 1 & 1 & 1 & 67 & Included \\
Commendador (2011) & 0 & 1 & 1 & 1 & 1 & 1 & 83 & Included \\
Doğan and Kazak (2010) & 0 & 0 & 1 & 1 & 1 & 1 & 67 & Included \\
Euser et al. (2013) & 1 & 1 & 1 & 1 & 1 & 1 & 100 & Included \\
Germeijs and Verschueren (2009) & 0 & 1 & 1 & 1 & 1 & 1 & 83 & Included \\
Keller and Whiston (2008) & 0 & 1 & 1 & 1 & 1 & 1 & 83 & Included \\
Koumoundourou et al. (2011) & 1 & 1 & 1 & 1 & 1 & 1 & 100 & Included \\
Lease and Dahlbeck (2009) & 0 & 0 & 1 & 1 & 1 & 1 & 67 & Included \\
Michael et al. (2013) & 0 & 0 & 1 & 1 & 1 & 1 & 67 & Included \\
Parishani and Nilforooshan (2014) & 1 & 0 & 1 & 1 & 1 & 1 & 83 & Included \\
Pérez and Cumsille (2012) & 0 & 1 & 1 & 1 & 1 & 1 & 83 & Included \\
Smits et al. (2008) & 0 & 1 & 0 & 1 & 0 & 0 & 33 & Excluded \\
Sovet and Metz (2014) & 0 & 1 & 1 & 1 & 1 & 1 & 83 & Included \\
Wolff and Crockett (2011) & 1 & 1 & 1 & 0 & 1 & 1 & 83 & Included \\
Yang et al. (2014) & 0 & 1 & 1 & 1 & 1 & 1 & 83 & Included \\
\hline
\end{tabular}

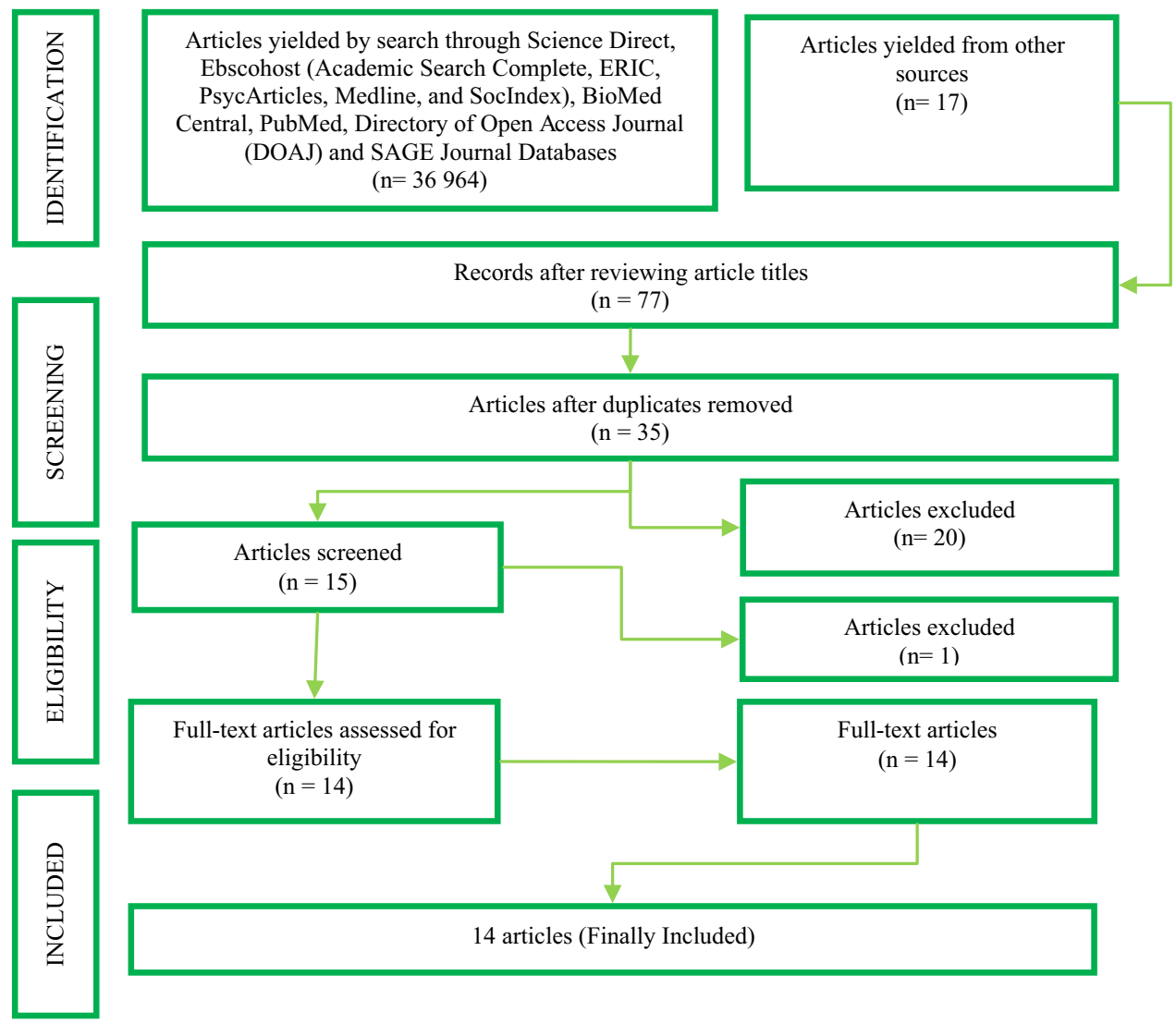

studies (Euser et al. 2013; Wolff and Crockett 2011; Germeijs and Verschueren 2009). The geographical location of the studies included four studies in the United States (Commendador 2011; Wolff and Crockett 2011; Lease and Dahlbeck 2009; Keller and Whiston 2008), three studies in Europe (Belgium, South Holland and Greece) (Euser et al.
2013; Koumoundourou et al. 2011; Germeijs and Verschueren 2009), three studies in Asia (Cheung et al. 2014; Parishani and Nilforooshan 2014; Michael et al. 2013), one study in South America (Chile) (Pérez and Cumsille 2012) one study from Turkey, which is between Europe and Asia (Doğan and Kazak 2010), and two intercontinental studies, 


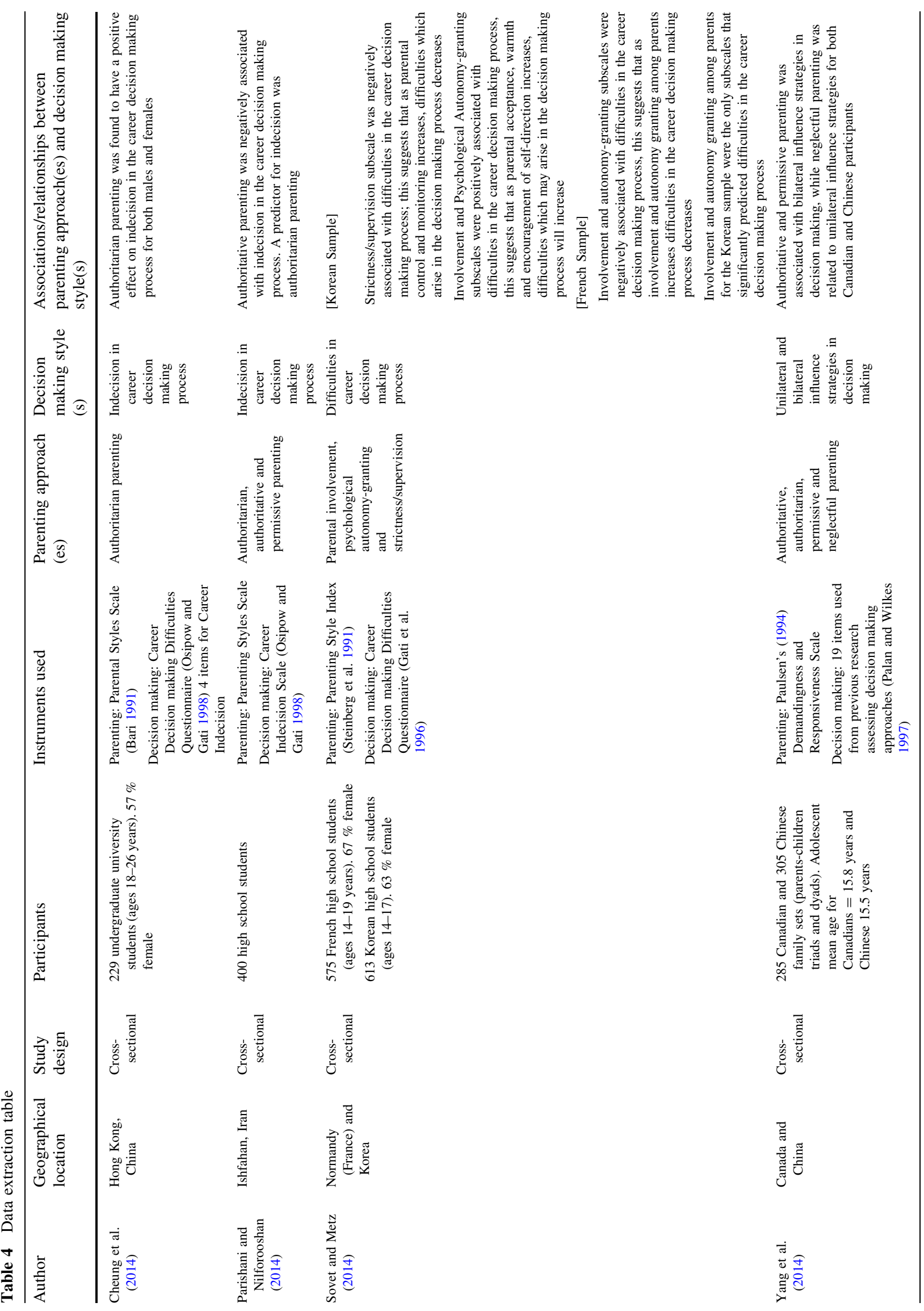




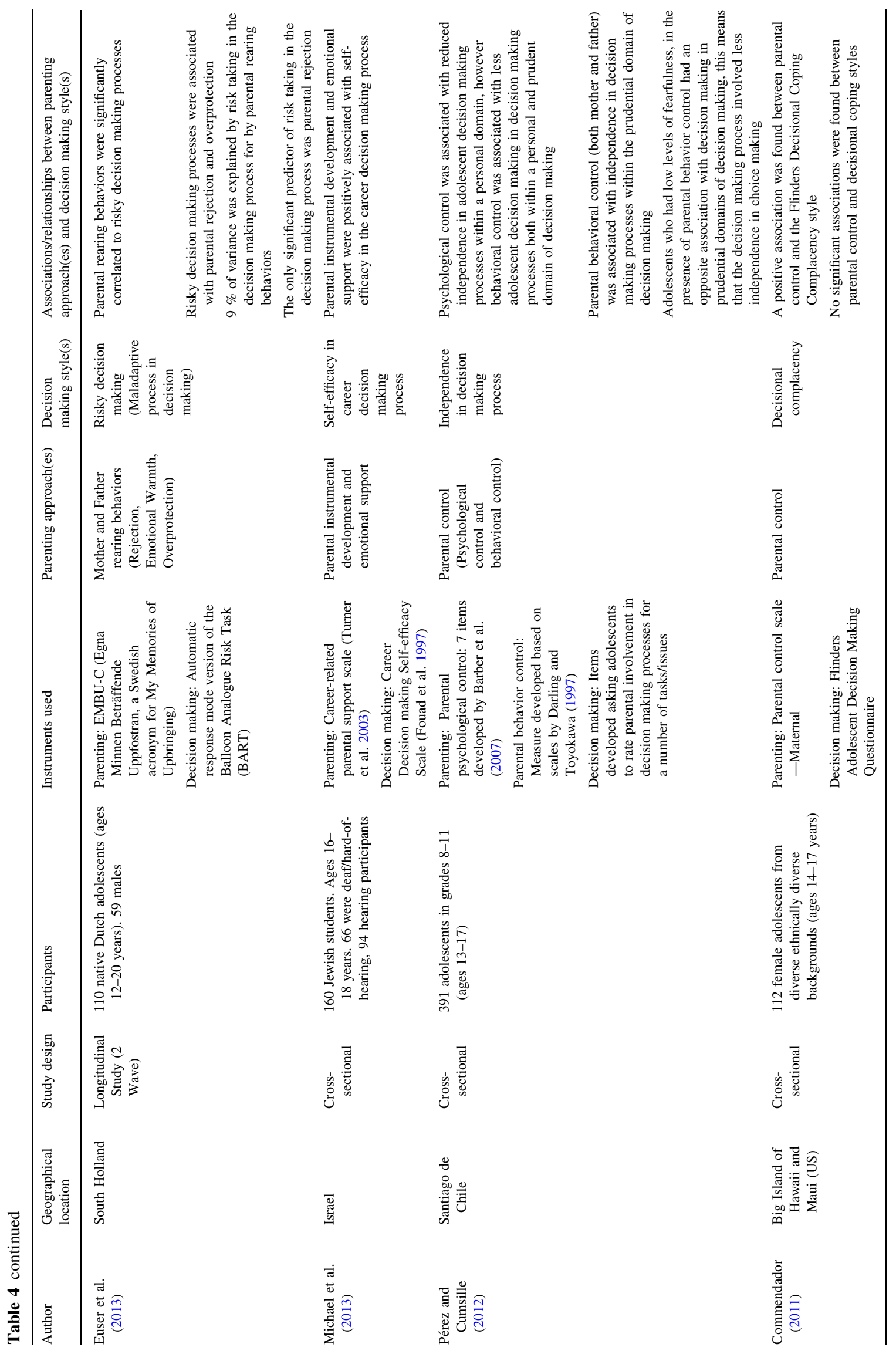




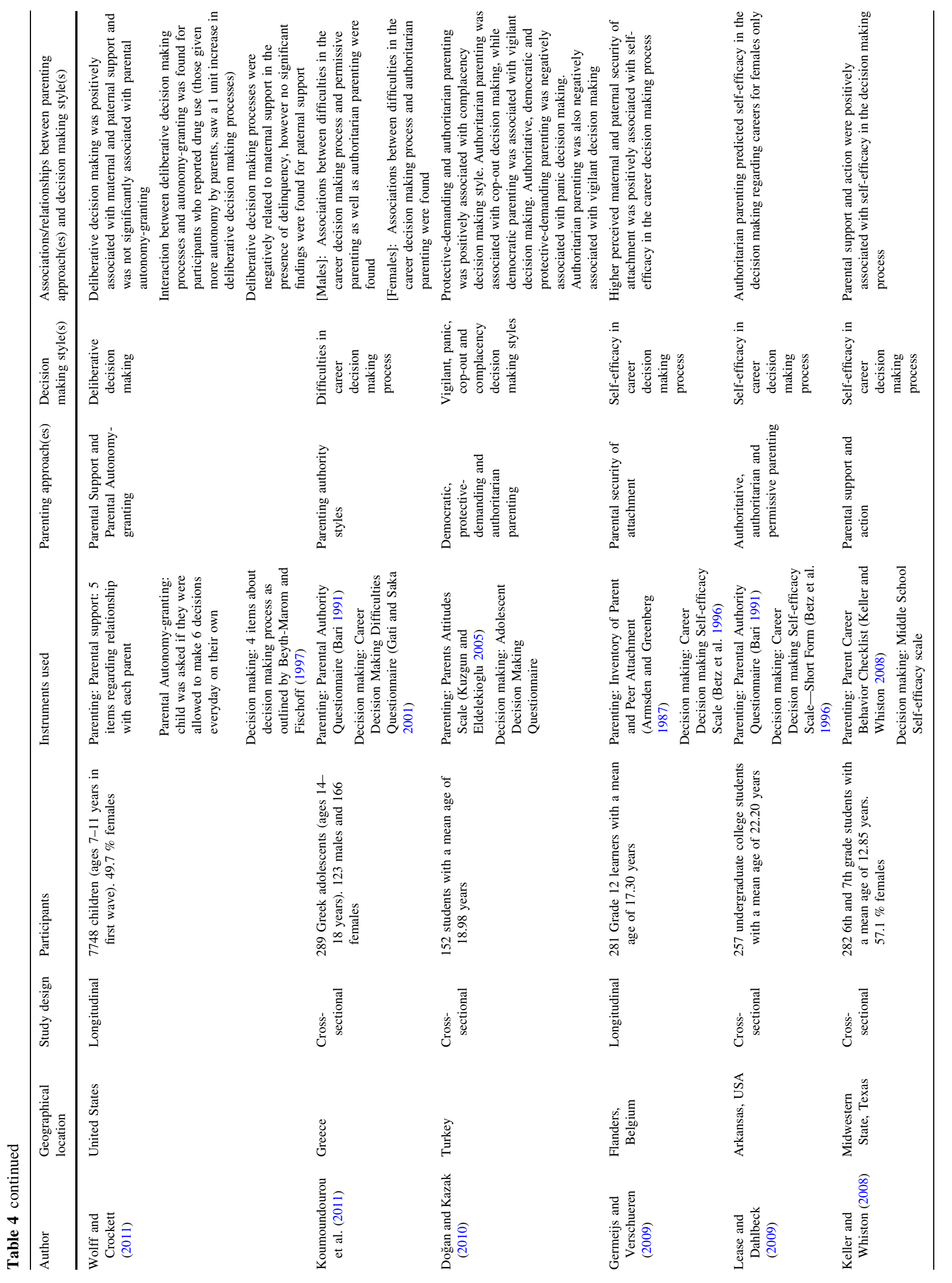


one between Europe and Asia (France and Korea) (Sovet and Metz 2014) and the other between the United States and Asia (Canada and China) (Yang et al. 2014). The ages of the participants in the studies ranged from 7 to 26 years.

\section{Decision Making Styles}

As a myriad of decisional making styles or processes were examined in the 14 studies, the various definitions of decision making processes or styles were categorized into being either adaptive or maladaptive decision making styles, based on the definitions presented in Table 5. The results presented in Table 5 suggest that the maladaptive decision making style was the most prevalent style of decision making among the studies in the review (Cheung et al. 2014; Parishani and Nilforooshan 2014; Sovet and Metz 2014; Yang et al. 2014; Koumoundourou et al. 2011; Euser et al. 2013; Pérez and Cumsille 2012; Commendador 2011; Doğan and Kazak 2010). Based on the decision making styles presented in Table 4, seven studies reported using the adaptive decision making style (Yang et al. 2014; Michael et al. 2013; Wolff and Crockett 2011; Doğan and Kazak 2010; Germeijs and Verschueren 2009; Lease and Dahlbeck 2009; Keller and Whiston 2008) (Table 5). The decision making styles which were categorized into the maladaptive decision making style were related to (1) difficulties in the career decision making process (Koumoundourou et al. 2011; Sovet and Metz 2014); (2) risky decision making (maladaptive processes in decision making) (Euser et al. 2013); (3) the lack of independence in decision making processes (Pérez and Cumsille 2012); (4) decisional complacency (Commendador 2011; Doğan and Kazak 2010); (5) decisional panic and (6) cop-out (Doğan and Kazak 2010); (7) indecision (Cheung et al. 2014; Parishani and Nilforooshan 2014); and (8) unilateral influences in decision making (Yang et al. 2014).

\section{Parenting Approaches}

In the review, the complexity in parenting is displayed in the number of parenting approaches examined in the various studies (Table 4). The parenting approaches were grouped into being either positive or negative parenting approaches based on the definition of the approaches used in the studies examined (Table 6). Nineteen parenting approaches were identified in the 14 studies reviewed; the negative parenting approach was the most prevalent parenting approach in the reviewed studies (Cheung et al. 2014; Parishani and Nilforooshan 2014; Yang et al. 2014; Euser et al. 2013; Pérez and Cumsille 2012; Koumoundourou et al. 2011; Commendador 2011; Doğan and Kazak 2010; Lease and Dahlbeck 2009), and positive parenting the least prevalent (Parishani and Nilforooshan
2014; Yang et al. 2014; Michael et al. 2013; Wolff and Crockett 2011; Doğan and Kazak 2010; Germeijs and Verschueren 2009; Keller and Whiston 2008). The studies by Parishani and Nilforooshan (2014), Yang et al. (2014), Sovet and Metz (2014) and Doğan and Kazak (2010) included both positive and negative parenting approaches.

Based on the parenting approaches presented in Table 4 and the definitions of the approaches (Table 6), nine parenting approaches were categorized as positive parenting approaches, namely: (1) authoritative parenting (Parishani and Nilforooshan 2014; Yang et al. 2014), (2) parental involvement and (3) autonomy granting (Sovet and Metz 2014), (4) parental instrumental development and (5) parental emotional support (Michael et al. 2013), (6) parental support (Wolff and Crockett 2011; Keller and Whiston 2008), (7) democratic parenting (Doğan and Kazak 2010), (8) attachment (Germeijs and Verschueren 2009) and (9) parental action (Keller and Whiston 2008). Ten approaches presented in the studies reviewed were categorized as being negative parenting approaches, namely: (1) authoritarian parenting (Cheung et al. 2014; Parishani and Nilforooshan 2014; Yang et al. 2014; Koumoundourou et al. 2011; Doğan and Kazak 2010; Lease and Dahlbeck 2009), (2) parental strictness (Sovet and Metz 2014), (3) permissive parenting (Yang et al. 2014; Koumoundourou et al. 2011), (4) neglectful parenting (Yang et al. 2014), (5) parental rejection and (6) overprotection (Euser et al. 2013), (7) psychological control and (8) behavior control (Pérez and Cumsille 2012) which are forms of (9) parental control were presented in the study by Commendador (2011), and (10) protective-demanding parenting (Doğan and Kazak 2010).

\section{Associations Between Decision Making Styles and Parenting Approaches}

The studies in this systematic review analyzed the relationships between decision making styles and the approaches to parenting. When considering the associations from the perspective of an adaptive and maladaptive decision making style, six studies had a positive association between the adaptive decision making style and positive parenting approaches (Yang et al. 2014; Michael et al. 2013; Wolff and Crockett 2011; Doğan and Kazak 2010; Germeijs and Verschueren 2009; Keller and Whiston 2008) (Tables 4, 5). Maladaptive decision making, however, was positively associated with ten negative parenting approaches in seven studies (Cheung et al. 2014; Yang et al. 2014; Euser et al. 2013; Pérez and Cumsille 2012; Commendador 2011; Koumoundourou et al. 2011; Doğan and Kazak 2010) (Tables 4, 5). For Korean participants, maladaptive decision making was positively associated with positive parenting approaches, and 
Table 5 Associations between decision making styles and parenting approaches

Decision making process
Adaptive decision making
Adaptive decision making often involve
processes which bring about the best possible
courses of action in the life domain in which the
decision needs to be taken (Avsec 2012). When
considering adaptive decision making some of
the common synonyms that accompany this style
of decision making are "methodical, systematic,
[and] independent" (Phillips 1997)
[and] independent" (Phillips 1997)

\section{Maladaptive decision making}

In maladaptive decision making stress is common. The presence of stress leads to diminished attempts to consider alternatives when faced with a situation in which a decision needs to be taken (Okwumabua et al. 2003).

Maladaptive decision making furthermore brings about indecisiveness and a lack of interest and concern about the best course of action that needs to be taken in the decision making process (Friedman and Mann 1993; Okwumabua et al. 2003)

$$
\text { Decision making style }
$$

Association with parenting approach

Wolff and Crockett (2011) and Doğan and Kazak (2010): the process of decision making involved thinking through all the possible alternatives before a behavioral outcome was selected. This process/style of decision making included: (1) considering possible alternatives as well as consequences, (2) appraising the "desirability" of the possible consequences as well as (3) considering the impact of each possible course of action and (4) collating all the steps taken and reevaluating the options that would yield the most desirable outcome for the decision maker

Yang et al. (2014): the process of decision making considered the individual as being someone who can successfully make decisions that have positive outcomes. The bilateral influence strategies employed in the decision making process involved reasoning and bargaining as part of the process of selecting an alternative with the most desirable outcome

Michael et al. (2013), Germeijs and Verschueren (2009), Lease and Dahlbeck (2009) and Keller and Whiston (2008): the decision making process was defined in light of the use of self-efficacy which considered the levels of confidence, gathering and appraising of information, planning as well as considering alternatives as part of the problem-solving process in decision making

Sovet and Metz (2014) and Koumoundourou et al. (2011): in these studies, the difficulties in the decision making process considered the following as being present (1) lack of motivation, (2) general indecisiveness about the course of action to take, (3) dysfunctional beliefs about the satisfaction of the decisional process at hand, (4) lack of sufficient information about the course of action to be taken
Positively associated

Parental support (Wolff and Crockett 2011) (+PA)

Democratic parenting (Doğan and Kazak 2010) (+PA)

Negatively associated Authoritarian parenting (Doğan and Kazak 2010) (-PA)

Positively associated

Authoritative (+PA) and permissive (-PA) parenting for both Chinese and Canadian participants

Positively associated

Parental instrumental development and emotional support (Michael et al. 2013) (+PA)

High perceived maternal and paternal security of attachment (Germeijs and Verschueren 2009) (+PA)

Predicted authoritarian parenting for females only (Lease and Dahlbeck 2009) (-PA)

Parental support and action (Keller and Whiston 2008) (+PA)

Sovet and Metz (2014)

Negatively associated

Parental strictness (Korean adolescents) (-PA)

Parental involvement (French adolescents) (+PA)

Autonomy-granting (French adolescents) (+PA)

Positively associated

Parental involvement (Korean adolescents) (+PA)

Autonomy-granting (Korean adolescents) (+PA)

Koumoundourou et al. (2011)

Positively associated

Authoritarian parenting (both genders) (-PA)

Permissive parenting (Males only) (-PA) 
Table 5 continued

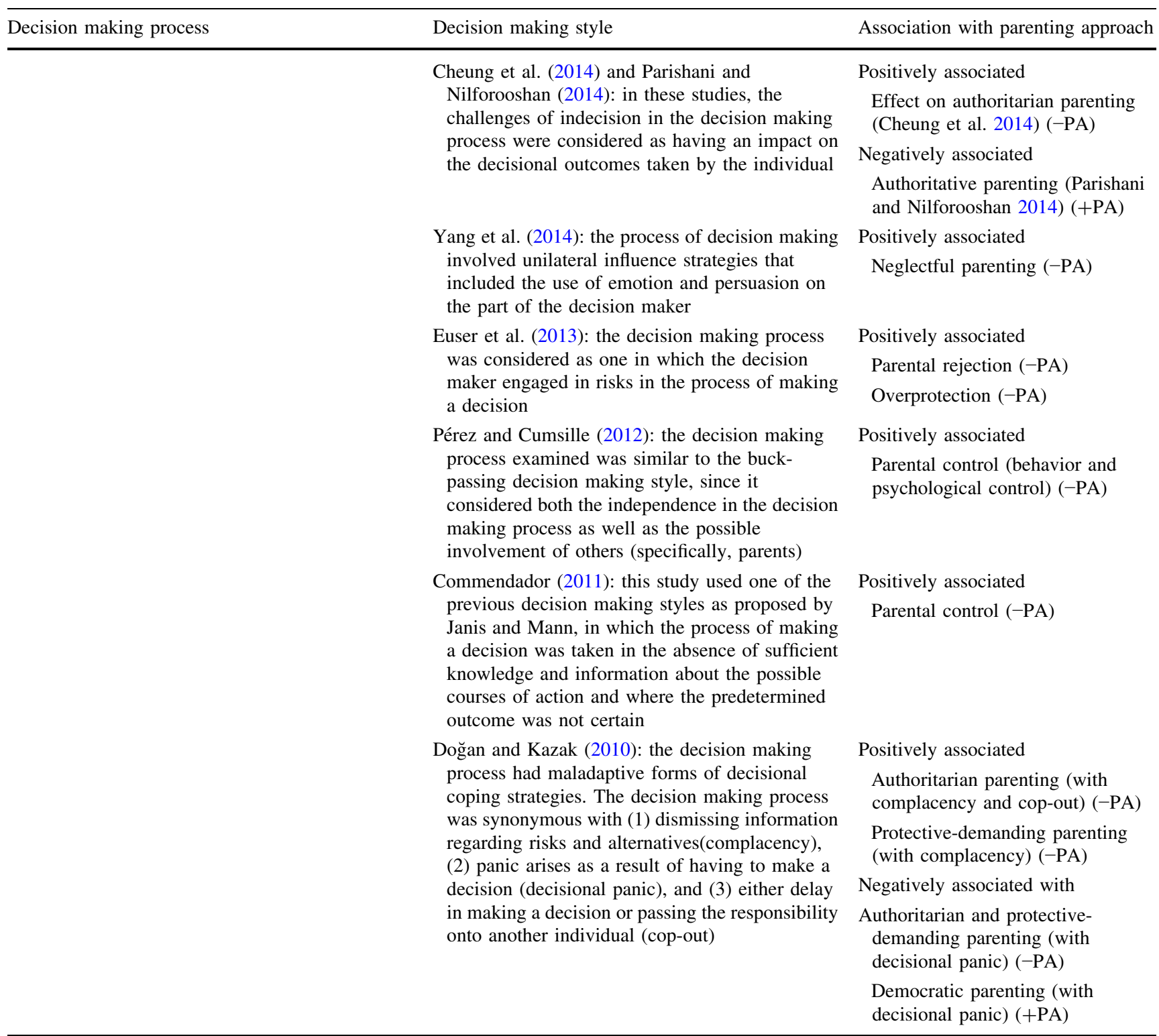

$+P A$ positive parenting approach, $-P$ A negative parenting approach

negatively associated with negative parenting approaches. Positive parenting approaches were also negatively associated with maladaptive decision making for French participants in one of the intercontinental studies (Sovet and Metz 2014). The findings for the Korean and French studies suggest that society, whether from a western or non-western society, could play a role in the association between parenting approaches and decision making styles. The role of society may also be contradictory, because the intercontinental study by Yang et al. (2014) found no differences between the western and non-western societal groups. The results indicate that the positive association between maladaptive decision making and negative parenting approaches was the most common association established in the review (Table 5).

\section{Discussion}

Often, situations arise in which a decision needs to be made. The process of arriving at an alternative that would be considered the best course of action for the decision making situation is defined as the decision making style (Scott and Bruce 1995; Leykin and DeRubeis 2010). 
Table 6 Positive and negative parenting approaches

Parenting approach $\quad$ Author(s) Parenting approach definition

Positive parenting approaches

Parenting approaches that are often related to pro-social or socially acceptable outcomes for children (Davids and Roman 2014), and involves nurturing, assistance, and monitoring in the parent-child relationship (Lee et al. 2006)
Parishani and Nilforooshan (2014) and Yang et al. (2014)

Sovet and Metz (2014)

Michael et al. (2013)

Wolff and Crockett (2011)

Doğan and Kazak (2010)

Germeijs and Verschueren (2009)

Keller and Whiston (2008)

Negative parenting approaches

Parental behaviors and approaches that hinder positive psychosocial development in children and adolescents (Betts et al. 2013), and child rearing that often takes place in the presence of poor monitoring and supervision, inconsistent or harsh forms of discipline (Barry et al. 2008)
Cheung et al. (2014), Parishani and Nilforooshan (2014), Yang et al. (2014), Koumoundourou et al. (2011), Doğan and Kazak (2010) and Lease and Dahlbeck (2009)

Sovet and Metz (2014)
Authoritative parenting: Parenting that is characterized by the display of warmth and support, while maintaining firm control (Yang et al. 2014)

Parental involvement: An approach to parenting where there is a display of warmth and acceptance (Vignoli et al. 2005; Sovet and Metz 2014)

Autonomy granting: Parenting approaches that allow for independence and self-exploration of alternatives

Parental instrumental development: Parenting that is characterized by providing and assisting children with information that would benefit them (Michael et al. 2013)

Parental emotional support: The display of support, emotionally by parents, with regard to concerns the child may have (Michael et al. 2013)

Parental support: Parenting that is characterized by "involvement, closeness, warmth, communication, and nurturance" (Holmbeck et al. 1995; Wolff and Crockett 2011)

Democratic parenting: Parenting that allows children and adolescents to display autonomy in child rearing (Doğan and Kazak 2010)

Security of attachment: The quality of attachment displayed within the parent-child relationship (Germeijs and Verschueren 2009)

Parental support: The display of psychosocial support by parents (Keller and Whiston 2008)

Parental action: Parenting behaviors related to events in the lives of children and adolescents (Keller and Whiston 2008)

Authoritarian parenting: A parenting style in which there is an expectation of obedience from children and adolescents, where the aim is to achieve control by use of punishment (Baumrind 1971; Koumoundourou et al. 2011)

Parental strictness: Parenting that is synonymous with demanding parents, the use of punitive disciplining styles and that is restrictive (Chua 2011; Sovet and Metz 2014)

Yang et al. (2014) and Koumoundourou et al. Permissive parenting: One of Baumrind's (2011)
(1971) parenting styles where there is a display of little to no control over children and adolescent's behavior in the presence of warmth displayed to children (Koumoundourou et al. 2011) 
Table 6 continued

\begin{tabular}{|c|c|c|}
\hline Parenting approach & Author(s) & Parenting approach definition \\
\hline & Yang et al. (2014) & $\begin{array}{l}\text { Neglectful parenting: Parents who display this } \\
\text { type of parenting often offer no form of } \\
\text { structure or monitoring for children and } \\
\text { adolescents, which comes across as being } \\
\text { neither demanding nor responsive (Yang } \\
\text { et al. 2014) }\end{array}$ \\
\hline & \multirow[t]{2}{*}{ Euser et al. (2013) } & $\begin{array}{l}\text { Parental rejection: When parents display } \\
\text { hostility and punishment, and were blaming } \\
\text { the child by the parent is common (Euser } \\
\text { et al. 2013) }\end{array}$ \\
\hline & & $\begin{array}{l}\text { Overprotection: Parenting where there is a } \\
\text { display of excessive parental control (Euser } \\
\text { et al. 2013) }\end{array}$ \\
\hline & \multirow[t]{2}{*}{ Pérez and Cumsille (2012) } & $\begin{array}{l}\text { Psychological control: A form of parental } \\
\text { control in which manipulation is common } \\
\text { and it interferes in the emotional and } \\
\text { psychological development of the child or } \\
\text { adolescent (Barber 1996; Pérez and } \\
\text { Cumsille 2012) }\end{array}$ \\
\hline & & $\begin{array}{l}\text { Behavior control: Parental control where } \\
\text { attempts are made to control the child and } \\
\text { adolescent behavior (Barber 1996; Pérez and } \\
\text { Cumsille 2012) }\end{array}$ \\
\hline & Commendador (2011) & $\begin{array}{l}\text { Parental control: Parenting where there are } \\
\text { attempts made to monitor children by setting } \\
\text { strict rules (Roche et al. 2005; } \\
\text { Commendador 2011) }\end{array}$ \\
\hline & Doğan and Kazak (2010) & $\begin{array}{l}\text { Protective-demanding parenting: Parenting } \\
\text { which is synonymous with high levels of } \\
\text { control with the aim of children and } \\
\text { adolescents conforming to the views of } \\
\text { parents (Doğan and Kazak 2010) }\end{array}$ \\
\hline
\end{tabular}

Individuals differ in their decision making styles (Riaz et al. 2012; Williams and Esmail 2014). The decision making style often is thought of as how individuals make sense of the information that is available for the alternatives as part of the decision making process (Albert and Steinberg 2011). The decision making style that individuals engage in before selecting an alternative operate on a continuum from adaptive to maladaptive decision making styles, when considering the plethora of decision making styles proposed by theorists and researchers (Galotti et al. 2006). When considering decision making styles of children and adolescents, parents are considered to play an important role (Udell et al. 2008). The approaches to parenting used by parents - positive or negative in nature-are associated with a number of developmental outcomes (Betts et al. 2013). The review, therefore, aimed to examine and describe previous studies that considered the associations between decision making styles and parenting approaches as decision making is often thought to take place in a social context, which usually is the parental home of the children and adolescents (Wolff and Crockett 2011).

\section{Overview of Studies}

The aim of this review was to examine the relationship between decision making styles and parenting approaches. There were some interesting points when one considers the demographic details of the participants in the studies in the review. The age of participants in the various studies in the review ranged from 7 to 26 years of age, with studies on emerging adolescence and adolescence being most prevalent. This developmental age group is commonly associated with risk-taking and maladaptive approaches to decision making (Reyna and Farley 2006). The participants from the studies in the review were largely representative of the United States of America, Europe, Asia, and South America. Some continents have very little research available on the associations examined, as can be seen from the lack of studies in the systematic review that were from Africa and Australia. 


\section{How do Children and Adolescents make Decisions?}

A number of theorists, over the years, have proposed an array of decision making styles (Gati et al. 2010). These decision making styles include Janis and Mann's (1977) conflictual model of decision making. The model proposes decision making styles that operate from vigilant to defensive avoidant decision making. Vigilant decision making is where a systematic process is followed in order to arrive at a decision which would yield the best possible outcome for the individual. Defensive avoidant forms of decision making are characterized by the possibility of delaying making a decision, shifting responsibility for making a decision or having insufficient time to make a decision.

In contrast, the styles proposed by Harren (1979), which were later extended by Scott and Bruce (1995), indicated that the different approaches that individuals use when making a decision could range from a rational and thorough investigation of possible alternatives to forms of decision making based on emotion, the assistance of others, avoidance of taking action and spontaneous decision making. Johnson (1978) proposed decision making styles that focus specifically on the manner individuals gather information, and how they understand it. More recent studies examining decision making styles have also been proposed by Leykin and DeRubeis (2010). That identifies nine decision making styles that range from a methodical and systematic approach, to examining alternatives to those which are dependent, spontaneous, avoidant and anxious forms of decision making.

The examination of some of the decision making styles that exist, moreover, provides an understanding of the plethora of decision making styles that exist in literature. However, one of the common trends in the various forms of decision making styles does exist. It is to establish whether the processes that the decision maker uses are those that could yield the best course of action (adaptive decision making) or whether they would hinder or interrupt attempt to achieve the best course of action (maladaptive decision making). In this review, the decision making styles were categorized into either adaptive or maladaptive decision making styles (Cenkseven-Önder 2012; Janis and Mann 1977; Parker et al. 2007), because a number of overlapping styles have been found (Leykin and DeRubeis 2010).

The literature presents a number of decision making styles that can be categorized into either adaptive or maladaptive decision making styles. Adaptive decision making is often thought of as being those decision making processes that assist and contribute to successful outcomes in a number of the decision maker's life domains (Avsec 2012). Furthermore, it is seen as a systematic and rigorous selecting of alternatives aimed at achieving the best outcome.
On the other hand, maladaptive decision making styles are those often with diminished attempts to consider alternatives when faced with a situation, or with attempts that do not always have the best course of action in mind (Okwumabua et al. 2003). When considering the decision making styles presented in this review, the most prevalent decision making style was the maladaptive form of decision making.

Maladaptive decision making styles have important implications for child and adolescent development. These implications can be detrimental to development. Research suggests that some of the implications of maladaptive decision making on children and adolescents are the development of low self-esteem (Leykin and DeRubeis 2010; Avsec 2012), depressive symptomology (Di Fabio 2006; Avsec 2012), and negative life events as a result of poor decision making approaches (Parker et al. 2007; Avsec 2012). These also include engaging in risky behavior and risk-taking (Reyna and Farley 2006; Williams and Esmail 2014), diminished health promoting behavior (Commendador 2007), low life satisfaction (CenksevenÖnder 2012), and increased perceived stress (Thunholm 2004). In addition to these implication, some researchers have found links to diminished physical and psychological well-being (Reyna and Farley 2006) and other researchers have found greater dependence on others (Parker et al. 2007), increased experience of regret (Parker et al. 2007), less decisional competence (Commendador 2011) and diminished health behavior (Steinberg 2004; Wolff and Crockett 2011). There is no doubt that maladaptive decision making styles have a number of implications for the developing child and adolescent.

\section{Understanding Parenting Approaches and the Relationship with Child and Adolescent Outcomes}

From a developmental perspective, parenting plays an important role in the development of children and adolescents (Aunola and Nurmi 2005; Lansford et al. 2005; Roopnarine et al. 2006). Parenting has a number of interacting factors (such as personal stresses or societal demands) that could play a role in their approaches to parenting (Belsky 1984; Thomson et al. 2014). Of interest have been the effects of parenting on the development of parent-child relationships (Aunola and Nurmi 2005; Chan and Koo 2011; Betts et al. 2013; Arnett 2014).

The parenting approaches that parents often use could be seen as either promoting pro-social behavior and development (positive parenting approaches) (Kaiser et al. 2011; Davids and Roman 2014) or as hindering the development of pro-social development and favor diminished adaptive development in children and adolescents (negative 
parenting approaches) (Betts et al. 2013; Dallaire et al. 2006; Whittaker and Cornthwaite 2000). The effects of these approaches of parenting are important because they have implications on development throughout the lifespan (Thomson et al. 2014). A number of parenting approaches exist in the literature (Wood et al. 2003; Aunola and Nurmi 2005) that were categorized into positive and negative parenting approaches for the purposes of this review.

The most prevalent parenting approach presented in this review was negative parenting. Negative parenting approaches have a number of adverse implications on child and adolescent development that include conduct disorder, behavioral problems, diminished autonomy, delinquency, onset of risky sexual behavior, indecisive decision making, diminished self-esteem, and lower levels of well-being and scholastic achievement (Baumrind 1989; Ferrari and Olivette 1993; Leung et al. 1998; Petersen et al. 1999; Jewell and Stark 2003; Aunola and Nurmi 2005; Roche et al. 2005; Supple and Small 2006). In contrast, positive parenting approaches have been associated with the most desirable and socially accepted outcomes for child and adolescent development (Baumrind 1991; Aunola and Nurmi 2005; Rinaldi and Howe 2012; Davids and Roman 2014).

\section{Decision Making Styles as an Outcome of Parenting Approaches}

Parenting approaches, over the centuries, have been associated with a number of developmental outcomes on children and adolescents (Davids and Roman 2014; Aunola and Nurmi 2005; Lansford et al. 2005). According to Western research, the approaches to parenting that are often associated with positive developmental outcomes are those that promote parental warmth and autonomy (Betts et al. 2013; Aunola and Nurmi 2005; Supple and Small 2006). Approaches to parenting that lack displays of warmth, and which hinder autonomous development and freedom, were associated with detrimental developmental outcomes for children and adolescents (Jewell and Stark 2003; Aunola and Nurmi 2005; Roche et al. 2005; Supple and Small 2006). The results presented in this review support this commonly-held notion in Western research, as a positive association was found between maladaptive decision making and negative parenting. The results indicate that, when parents display or engage in approaches to parenting that are deemed negative, this has detrimental outcomes for child and adolescent decision making, as the child or adolescent would be prone to engage in maladaptive decision making.

Engaging in maladaptive decision making has a number of negative implications for the developing child. These implications include diminished behavior that affects health and well-being, depressive symptomology, negative life events as a result of poor decision making, and engaging in risky behavior and risk-taking (Di Fabio 2006; Jewell and Stark 2003; Roche et al. 2005). These associations, however, are not deemed universal and applicable across different societal groups (Supple and Small 2006; Maiter and George 2003).

Western societies that promote parental warmth and autonomy have been most prevalent in the studies reviewed. One intercontinental study, between French and Asian participants, found negative parenting approaches associated with maladaptive decision making, whereas positive parenting was positively associated with maladaptive decision making for Asian participants. This contradictory association suggests that society (whether western or non-western) may play an important role in the association between parenting approaches and decision making styles. However, it also leaves room to question whether these findings are always true from a cross-societal, cross-continental perspective, since Yang et al. (2014) found no significant differences between adolescents from the United States and Asia.

Western societies promote parenting that display warmth and promote autonomy, while parenting in Asian (non-Western or ethnic minority groups) societies promotes more restrictive and authoritarian parenting (Supple and Small 2006; Maiter and George 2003; Parke 2000). The ideal on which Western society is based is that of personal development and independence, while non-Western societies are based on the development of the group and interdependence (Supple and Small 2006; Aunola and Nurmi 2005; Bush et al. 2002). From a societal perspective, this could partially explain the contradictory associations of both negative and positive parenting with maladaptive decision making. Society, western or non-western in nature, plays an important role in the behavioral and social development of individuals (Ferguson et al. 2013; Roets et al. 2012; Ferguson 2000).

Society influences the understanding that individuals have, of numerous experiences in societal contexts. This can be seen in the results presented in the review (Hofstede 2007). The differences in how individuals engage in social experiences, as a result of society, can impact parenting, and the approaches that parents use in the parent-child relationship (Ferguson et al. 2013; Bornstein and Cote 2006; Parmar et al. 2004). The contradictory findings in the two intercontinental studies that examined the associations between decision making styles and parenting approaches can be explained by western and non-western societal differences. The contradictory findings can be the result of either enculturation or acculturation. Enculturation is the socialization process where the family or parental home environment clings to the societal norms and values in 
which the parents were raised (Choi et al. 2013). This was at work in the review by Pérez and Cumsille (2012), in which parents from the non-western society clung to the societal norms and values with regards to parenting. Holding those values and norms explained the association of positive parenting approaches with maladaptive decision making, which were different for the participants from the western society in the study. On the other hand, acculturation relates to adapting to mainstream societal values and practices, which are common due to the influence of globalization (Choi et al. 2013). Yang et al.'s (2014) can be explained by acculturation. With increasing globalization, non-western societies tend to adapt to mainstream western norms and values with regards to parenting that explains the similarity found in the associations between parenting approaches and decision making styles for both the western and non-western societies examined in the study.

The study by Commendador (2011) examined the associations between parenting approaches and decision making styles of females only. Commendador (2011) found a positive association between maladaptive decision making and negative parenting approaches in a female only study, which is similar to findings in this review, except that this review included studies with both males and females (Euser et al. 2013; Pérez and Cumsille 2012; Koumoundourou et al. 2011). In the review, no gender differences were found in the associations between parenting approaches and decision making styles, while other studies have found significant differences between decision making styles and gender (Roman and Davids 2013; Sari 2008). The similarities between male and female associations between decision making styles and parenting approaches in the review can be due to males and females' being equally capable of considering alternatives and making sense of the decisional alternatives available to them (Brown et al. 2011). The review considered only the decision making processes or styles, and not the behavioral outcomes that are often associated with gender roles ascribed by society (Brown et al. 2011). This could be a reason why gender did not play a significant role in the association between parenting approaches and decision making styles in the review.

Reviewing the association between decision making styles and parenting is important, particularly as individuals are confronted with the task of making decisions daily. The current systematic review contributes to the existing body of knowledge by providing a summary of study designs, geographical locations and participant demographical details of studies examining the association between decision making styles and parenting approaches. The review also highlights some of the gaps and limitations in literature that can inform future research to advance adolescent development research.
Studies considering decision making often are concerned with the behavioral outcome of children and adolescent decision making. The current review presents the prevalent decision making styles in child and adolescent research studies, which would assist in policy and program development in best-practice guidelines for advancing adaptive decision making for children and adolescents. Additionally, the review provides an inclusive understanding of the processes that adolescents engage in as part of decision making styles. Decision making styles are important, particularly as adolescence is synonymous with behavioral decisions that are often thought to be detrimental to pro-social development (Monahan et al. 2013). In providing an understanding of the processes that adolescents engage in as part of decision making styles, the review addresses some of the concerns highlighted by Galotti et al. (2006) who have questioned the role that decision making styles play in the information-gathering process, which is examined in this review. The review provides a glimpse of the plethora of decision making styles that exist in the literature that often overlap one another; however, for the first time, the current review provides clear categories of different decision making styles. These categories are on a continuum of adaptive (such as deliberative and vigilant decision making styles) to maladaptive decision making styles (such as difficulties in decision making process, decisional panic and indecision).

The review also presents the global trends of the developmental association between decision making styles and parenting approaches of children and adolescents. This is important. In reviewing adolescent decision making, Albert and Steinberg (2011) have suggested that future research should consider the role of environmental factors such as peers and parents in light of decision making. The current review provides a comprehensive understanding of the association of decision making styles and parenting (in the parental home environment). It addresses the gaps in understanding adolescent decision making as alluded to by Albert and Steinberg (2011). The current review, moreover, adds to the understanding about the role that the social environment plays in decision making (Gardner and Steinberg 2005), more specifically decision making styles -by examining the associations from both a global and cross-societal perspective. This contribution is important when considering current debates around child and adolescent development in light of complex changes in the environment that either promote or hinder pro-social development for children, adolescents and youth (Coll 2015).

When considering the role of the parental environment and the role it plays, it is known that negative parenting approaches are associated with developmental outcomes that can be detrimental for children and adolescents. 
However, limited studies have presented the association of negative approaches to parenting with regard to decision making. The review confirms that negative parenting approaches are associated with maladaptive decision making styles. These findings warrant future research considering: (a) instrument development with scales for adaptive and maladaptive decision making styles, and (b) the associated parenting approaches either to confirm or refute the findings presented in the research.

One of the key findings of the review suggests that maladaptive decision making styles are associated with negative parenting. Even though it might be considered as not presenting new findings, most studies have focused on the behavioral outcomes (such as delinquent or risk behavior) of negative parenting. However, the review presents the relationship of negative parenting and the process of making a decision. The findings presented in the review are important for parenting interventions, as they provide motivation for the development of parenting interventions that focus on the interaction of parents with their children and adolescents in terms of decision making. Contemporary studies suggest that parents are largely focused on the behavioral outcomes of decision making, where the current review presents the importance of the decision making process.

The important role of parenting is discussed in the context of decision making, and the approaches that are associated with decision making styles throughout child and adolescent development. The review also provides practitioners, academics and policy makers with insight into the processes of decision making and the role that parents play, which contributes to programme and intervention development, as well as research and policies that would aid in the promotion of adaptive decision making styles of children and adolescents.

\section{Limitations and Recommendations}

Parenting is only one of many social contexts in which decision making styles can be examined. Therefore, limiting the associations of decision making styles to parenting only can be considered a limitation, since there are a number of contextual factors to consider in decision making. This could be considered as recommendations for future research. Another limitation is that the review was not able to examine the relationships that sons and daughters have with their maternal and paternal parenting figures. Future research could also attempt to examine the associations between decision making styles and (1) personality, (2) genetics, (3) other familial and social environments (other than the parental home environment), (4) socio-economic status, as well as (5) individualistic versus collectivistic societies. As more reviews become available examining child and adolescent decision making, it will assist in better understanding the relationships that exists between adaptive and maladaptive decision making.

\section{Conclusion}

Parenting approaches play an important role in the social development of children and adolescents. In particular, the various approaches to parenting have been associated with a number of psychosocial as well as behavioral outcomes. This review examined the associations between decision making styles and parenting approaches. The results indicate that there are distinct associations between decision making and parenting. Both adaptive and maladaptive decision making have been associated with parenting approaches, while maladaptive decision making styles were the most prevalent. The review suggests that maladaptive decision making was associated with negative parenting approaches. Often maladaptive decision making has been associated with detrimental developmental outcomes for both children and adolescents.

The current review provides a comprehensive understanding of the associations between decision making styles and parenting approaches-from a global perspectivewhere western and non-western societies were found to play an important role in the associations. Gender and age had no significant role in the associations presented. The review provides an understanding of the associations between decision making styles and parenting approaches, as well as bridging the gaps in literature and proposing recommendations for future research. Additionally, the review provides clear categories for delineating decision making styles into either adaptive or maladaptive decision making. The findings presented confirm that negative parenting is associated with maladaptive decision making, but the review reveals the need for future research with regards to the development of instruments and interventions for both research and practice. Moreover, the review adds to current debates and knowledge on children and adolescent's decision making processes. It confirms the important role that parents play in the development of styles of decision making.

Acknowledgments The authors would like to acknowledge the support of the National Research Foundation (NRF).

Conflict of interest The authors declare no conflict of interest.

\section{References}

Albert, D., \& Steinberg, L. (2011). Judgment and decision making in adolescence. Journal of Research on Adolescence, 21(1), 211224. 
Armsden, G. C., \& Greenberg, M. T. (1987). The inventory of parent and peer attachment: Individual differences and their relationship to psychological well-being in adolescence. Journal of Youth and Adolescence, 16, 427-454.

Arnett, J. J. (2014). Adolescence and emerging adulthood: A cultural approach. Boston: Prentice Hall.

Aunola, K., \& Nurmi, J. (2005). The role of parenting styles in children's problem behavior. Child Development, 76(6), 11441159.

Avsec, A. (2012). Do emotionally intelligent individuals use more adaptive decision making styles? Studia Psychologica, 54, 209220.

Barber, B. K. (1996). Parental psychological control: Revisiting a neglected construct. Child Development, 67, 3296-3319.

Barber, B. K., Olsen, J. A., Hunter, S. B., Schluterman, J. M., McNeely, C., \& Bose, K. (2007). Refining the measure of parental control: Integrating input from adolescents - a multidimensional construct. Paper presented at Biennial meeting of the Society for Research in Child Development, Boston.

Bari, J. R. (1991). Parental authority questionnaire. Journal of Personality Assessment, 57, 110-119.

Barry, C. T., Frick, P. J., \& Grafeman, S. J. (2008). Child versus parent reports of parenting practices: Implications for the conceptualization of child behavioral and emotional problems. Assessment, 15(3), 294-303.

Baumrind, D. (1971). Current patterns of parental authority. Developmental Psychological Monograph, 4, 1-102.

Baumrind, D. (1989). Rearing competent children. In W. Damon (Ed.), Child development today and tomorrow (pp. 349-378). San Francisco: Jossey-Bass.

Baumrind, D. (1991). The influence of parenting style on adolescent competence and substance use. Journal of Early Adolescence, 11, 56-95.

Belsky, J. (1984). The determinants of parenting: A process model. Child Development, 55(1), 83-96.

Betts, L. R., Trueman, M., Chiverton, L., Stanbridge, A., \& Stephens, J. (2013). Parental rearing style as a predictor of attachment and psychosocial adjustment during young adulthood. Journal of Social and Personal Relationships, 30(6), 675-693.

Betz, N. E., Klein, K. L., \& Taylor, K. M. (1996). Evaluation of a short form of the career decision making self-efficacy scale. Journal of Career Assessment, 4, 47-57.

Beyth-Marom, R., \& Fischoff, B. (1997). Adolescents' decisions about risks: A cognitive perspective. In J. Schulenberg, J. L. Maggs, \& K. Hurrelmann (Eds.), Health risks and developmental transitions during adolescence (pp. 110-135). Cambridge: Cambridge University Press.

Bornstein, M. H., \& Cote, L. R. (2006). Parenting cognitions and practices in the acculturative processes. In M. H. Bornstein \& L. R. Cote (Eds.), Acculturation and parent-child relationships: Measurement and development (pp. 173-196). New Jersey: Lawrence Erlbaum Associates.

Brand, S., Hatzinger, M., Beck, J., \& Holsboer-Trachsler, E. (2009). Perceived parenting styles, personality traits and sleep patterns in adolescents. Journal of Adolescence, 32, 1189-1207.

Brown, J., Adballah, S. S., \& Ng, R. (2011). Decision making styles East and West: Is it time to move beyond cross-cultural research? International Journal of Sociology and Anthropology, 3(12), 452-459.

Brown, J., \& Mann, L. (1990). The relationship between family structure and process variables and adolescent decision making. Journal of Adolescence, 13(1), 25-37.

Bruine de Bruin, W., Parker, A. M., \& Fischhoff, B. (2007). Individual differences in adult decision making competence. Journal of Personality and Social Psychology, 92(5), 938956.
Burnett, P. C. (1991). Decision making style and self-concept. Australian Psychologist, 26(1), 55-58.

Bush, K. R., Peterson, G. W., Cobas, J. A., \& Supple, A. J. (2002). Adolescents' perceptions of parental behaviors as predictors of adolescent self-esteem in Mainland China. Sociological Inquiry, $72,503-526$.

Cenkseven-Önder, F. (2012). The influence of decision making styles on early adolescents' life satisfaction. Social Behavior and Personality, 40(9), 1523-1536.

Chan, T. W., \& Koo, A. (2011). Parenting style and youth outcomes in the UK. European Sociological Review, 27(3), 385-399.

Chao, R. (2001). Extending research on the consequences of parenting style for Chinese Americans and European Americans. Child Development, 72, 1832-1843.

Cheung, C., Cheung, H. Y., \& Wu, J. (2014). Career unreadiness in relation to anxiety and authoritarian parenting among undergraduates. International Journal of Adolescence and Youth, 19 (3), 336-349.

Choi, Y., Kim, Y. S., Kim, H. J., \& Pekelnicky, D. D. (2013). Preservation and modification of culture in family socialization: Development of parenting measures for Korean immigrant families. Asian American Journal of Psychology, 4(2), 143-154.

Chua, A. (2011). Battle hymn of the tiger mother. New York: Penguin Books.

Coll, C. G. (2015). Editorial: Continuity and change in child development. Child Development, 86(1), 7-9.

Commendador, K. (2007). The relationship between female adolescent self-esteem, decision making and contraception. The Journal of American Academy of Nurse Practitioners, 19(11), 614-623.

Commendador, K. (2011). The relationship between maternal parenting style, female adolescent decision making, and contraceptive use. Journal of the American Academy of Nursing Practitioners, 23, 561-572.

Curşeu, P. L., \& Schruijer, S. G. L. (2012). Decision styles and rationality: An analysis of the predictive validity of the General Decision making Style Inventory. Educational and Psychological Measurement, 72(6), 1053-1062.

Dallaire, D. H., Pineda, A. Q., Cole, D. A., Ciesla, J. A., Jacquez, F., LaGrange, B., \& Bruce, A. E. (2006). Relation of positive and negative parenting to children's depressive symptoms. Journal of Clinical Child and Adolescent Psychology, 35(2), 313-322.

Darling, N., \& Toyokawa, T. (1997). Constructions and validation of the parenting style inventory II (PSI-II) (unpublished manuscript).

Davids, E. L., \& Roman, N. V. (2014). A systematic review of the relationship between parenting styles and children's physical activity. African Journal for Physical, Health Education, Recreation and Dance, 20 (Suppl 2:1), 228-246.

Di Fabio, A. (2006). Decisional procrastination correlates: Personality traits, self-esteem or perception of cognitive failure? International Journal for Educational and Vocational Guidance, 6, 109122.

Doğan, T., \& Kazak, M. (2010). The investigation of the relationship between students' decision making skills and parental attitudes. Procedia Social and Behavioral Sciences, 2, 2556-2560.

Driver, M. J., Brousseau, K., \& Hunsaker, P. L. (1990). The dynamic decision maker. New York: Harper and Row.

Euser, A. S., Evans, B. E., Greaves-Lord, K., Huizink, A. C., \& Franken, H. A. (2013). Parental rearing behavior prospectively predicts adolescents' risky decision making and feedback-related electrical brain activity. Developmental Science, 16(3), 409-427.

Faraci, P., Lock, M., \& Wheeler, R. (2013). Assessing leadership decision making styles: Psychometric properties of the leadership and Judgment indicator. Psychology Research and Behavior Management, 6, 117-123. 
Ferguson, E. D. (2000). Motivation: A biosocial and cognitive integration of motivation and emotion. New York: Oxford University Press.

Ferguson, E. D., Hagaman, J. A., Maurer, S. B., Mathews, P., \& Peng, K. (2013). Asian culture in transition: Is it related to reported parenting styles and transitivity of simple choices? Journal of Applied Social Psychology, 43, 730-740.

Ferrari, J. R., \& Olivette, M. J. (1993). Perceptions of parental control and the development of indecision among late adolescent females. Adolescence, 28, 963-970.

Fouad, N. A., Smith, P. L., \& Enochs, L. (1997). Reliability and validity for the Middle School Self-Efficacy Scale. Measurement and Evaluation in Counseling and Development, 30, 17-31.

Friedman, I. A., \& Mann, L. (1993). Coping patterns in adolescent decision making: An Israeli-Australian comparison. Journal of Adolescence, 16, 187-199.

Fuemmeler, B. F., Yang, C., Costanzo, P., Hoyle, R. H., Siegler, I. C., Williams, R. B., \& Østbye, T. (2012). Parenting styles and body mass index trajectories from adolescence to adulthood. Health Psychology, 31(4), 441-449.

Galotti, K. M. (2007). Decision structuring in important real-life choices. Psychological Science, 22(3), 275-287.

Galotti, K. M., Ciner, E., Altenbaumer, H. E., Geerts, H. J., Rupp, A., \& Woulfe, J. (2006). Decision making styles in a real-life decision: Choosing a college major. Personality and Individual Differences, 41, 629-639.

Gardner, M., \& Steinberg, L. (2005). Peer influence on risk taking, risk preference, and risky decision making in adolescence and adulthood: An experimental study. Developmental Psychology, 41, 625-635.

Gati, I., Krausz, M., \& Osipow, S. H. (1996). A taxonomy of difficulties in career decision making. Journal of Counseling Psychology, 43, 510-526.

Gati, I., Landman, S., Davidovitch, S., Asulin-Peretz, L., \& Gadassi, R. (2010). From career decision making styles to career decision making profiles: A multidimensional approach. Journal of Vocational Behavior, 76, 277-291.

Gati, I., \& Saka, N. (2001). High school students' career-related decision-making difficulties. Journal of Counseling and Development, 79, 331-340.

Germeijs, V., \& Verschueren, K. (2009). Adolescents' career decision making process: Related to quality of attachment to parents? Journal of Research on Adolescence, 19(3), 459-483.

Hardin, E. E., \& Leong, F. T. L. (2004). Decision making theories and career assessment: A psychometric evaluation of the decision making inventory. Journal of Career Assessment, 12(1), 51-64.

Harren, V. A. (1979). A model of career decision making for college students. Journal of Vocational Behavior, 14, 119-133.

Hofstede, G. (2007). A European in Asia. Asian Journal of Social Psychology, 10, 16-21.

Holmbeck, G. N., Paikoff, R. L., \& Brooks-Gunn, J. (1995). Parenting adolescents. In M. H. Bornstein (Ed.), Handbook of parenting (Vol. 1, pp. 91-118). New Jersey: Lawrence Erlbaum.

Janis, I. L., \& Mann, L. (1977). Decision making: A psychological analysis of conflict, choice and commitment. New York: The Free Press.

Jewell, J. D., \& Stark, K. D. (2003). Comparing the family environments of adolescents with conduct disorder and depression. Journal of Child and Family Studies, 12, 77-89.

Johnson, R. H. (1978). Individual styles of decision making: A theoretical model for counseling. Personnel and Guidance Journal, 56, 530-536.

Kaiser, N. M., McBurnett, K., \& Pfiffner, L. J. (2011). Child ADHD severity and positive and negative parenting as predictors of child social functioning: Evaluation of three theoretical models. Journal of Attention Disorders, 15(3), 193-203.
Keller, B. K., \& Whiston, S. C. (2008). The role of parental influences on young adolescents' career development. Journal of Career Assessment, 16(2), 198-217.

Kitamura, T., Uji, M., Chen, Z., Murakami, M., \& Goto, Y. (2014). Determinants of parenting styles of Japanese fathers and mothers with children aged 0 to 10 : Perceived parenting during childhood or dysphoric mood. Open Family Studies Journal, 6, 8-16.

Klaczynski, P. A. (2005). Metacognition and cognitive variability: A dual-process model of decision making and its development. In J. E. Jacobs \& P. A. Klaczynski (Eds.), The development of judgment and decision making in children and adolescents. New Jersey: Lawrence Erlbaum Associates.

Koumoundourou, G., Tsaousis, I., \& Kounenou, K. (2011). Parental influences on Greek adolescents' career decision making difficulties: The mediating role of core self-evaluations. Journal of Career Assessment, 19(2), 165-182.

Kuzgun, Y., \& Eldelekioğlu, J. (2005). Parents Attitudes Scale. In Y. Kuzgun \& F. Bacanli (Eds.), Scales used in counseling and guidance. Ankara: Nobel Publication.

Lansford, J. E., Chang, L., Dodge, K. A., Malone, P. S., Oburu, P., Palmerus, K., et al. (2005). Physical discipline and children's adjustment: Cultural normativeness as a moderator. Child Development, 76(6), 1234-1246.

Lease, S. H., \& Dahlbeck, D. T. (2009). Parental influences, career decision making attributes, and self-efficacy: Differences for men and women? Journal of Career Development, 36(2), 95113.

Lee, S. M., Daniels, M. H., \& Kissinger, D. B. (2006). Parental influences on adolescent adjustment: Parenting styles versus parenting practices. The Family Journal, 14(3), 253-259.

Leung, K., Lau, S., \& Lam, W. (1998). Parenting styles and academic achievement: A cross-cultural study. Merrill-Palmer Quarterly, 44, 152-172.

Leykin, Y., \& DeRubeis, R. J. (2010). Decision making styles and depressive symptomatology: Development of the Decision Styles Questionnaire. Judgment and Decision Making, 5(7), 506-515.

Louw, Q. A., Morris, L. D., \& Grimmer-Somers, K. (2007). The prevalence of low back pain in Africa: A systematic review. BMC Musculoskeletal Disorders, 8, 105.

Maccoby, E. E., \& Martin, J. A. (1983). Socialization in the context of the family: Parent-child interaction. In E. M. Hetherington \& P. H. Mussen (Eds.), Handbook of child psychology: Socialization, personality, and social development (4th ed., Vol. 4). New York: Wiley.

Madahi, A., Sukati, I., Mazhari, M. Y., \& Rashid, W. N. (2012). Consumer decision making styles amongst young generation in Malaysia. European Journal of Social Sciences, 30(2), 263275.

Maiter, S., \& George, U. (2003). Understanding context and culture in the parenting approaches of immigrant South Asian mothers. Affilia, 18(4), 411-428.

Michael, R., Most, T., \& Cinamon, R. G. (2013). The contribution of perceived parental support to the career self-efficacy of deaf, hard-of-hearing, and hearing adolescents. Journal of Deaf Studies and Deaf Education, 18, 329-343.

Miller, D. C., \& Byrnes, J. P. (2001). Adolescents' decision making in social situations: A self-regulation perspective. Journal of Applied Development Psychology, 22, 237-256.

Mokhlis, S., \& Salleh, H. S. (2009). Decision making styles of young Malay, Chinese and Indian consumers in Malaysia. Asian Social Science, 5(12), 50-59.

Monahan, K. C., Rhew, I. C., Hawkins, J. D., \& Brown, E. C. (2013). Adolescent pathways to co-occurring problem behavior: The effects of peer delinquency and peer substance use. Journal of Research on Adolescence, 24(4), 630-645. 
Moshman, D. (2011). Adolescent rationality and development: Cognition, morality, and identity. New York: Psychology Press.

Okwumabua, J. O., Wong, S. P., \& Duryea, E. J. (2003). Depressive symptoms and decision making among African American youth. Journal of Adolescent Research, 18(5), 436-453.

Osipow, S. H., \& Gati, I. (1998). Construct and concurrent validity of the career decision making difficulties questionnaire. Journal of Career Assessment, 6, 347-364.

Özütrk, N., Kutlu, M., \& Atli, A. (2011). The effect of parents' attitudes on adolescents' decision making strategies. Inonu University Journal of the Faculty of Education, 12(2), 45-64.

Palan, K. M., \& Wilkes, R. E. (1997). Adolescent-parent interaction in family decision making. Journal of Consumer Research, 24, $159-169$.

Parishani, N., \& Nilforooshan, P. (2014). Career indecision: Predictive role of parenting styles, emotional intelligence and career decision making self efficacy. Reef Resources Assessment and Management Technical Paper, 43(4), 15-26.

Parke, R. D. (2000). Beyond White and middle class: Cultural variations in families-Assessments, processes, and policies. Journal of Family Psychology, 14, 331-333.

Parker, A. M., Bruine de Bruin, W., \& Fischhoff, B. (2007). Maximizes versus satisficers: Decision making styles, competence, and outcomes. Judgment and Decision Making, 2(6), 342350 .

Parmar, P., Harkness, S., \& Super, C. M. (2004). Asian and EuroAmerican parents' ethnotheories of play and learning: Effects on preschool children's home routines and school behavior. International Journal of Behavioral Development, 28, 97-104.

Paulsen, S. E. (1994). Relations of parenting style and parental involvement with students' achievement. Journal of Early Adolescence, 14(2), 250-267.

Pérez, J. C., \& Cumsille, P. (2012). Adolescent temperament and parental control in the development of the adolescent decision making in a Chilean sample. Journal of Adolescence, 35, 659669.

Petersen, G. W., Bush, K. R., \& Supple, A. J. (1999). Predicting adolescent autonomy from parents: Relationship connectedness and restrictiveness. Sociological Inquiry, 69, 431-457.

Phillips, S. D. (1997). Toward an expanded definition of adaptive decision making. The Career Development Quarterly, 45, 275287

Phillips, J. G., \& Ogeil, R. P. (2011). Decisional styles and risk of problem drinking or gambling. Personality and Individual Differences, 51, 521-526.

Piaget, J. (1972). Intellectual evolution from adolescence to adulthood. Human Development, 15, 1-12.

Piaget, J. (2006). Reason. New Ideas in Psychology, 24, 1-29.

Putallaz, M., Constanzo, P. R., Grimes, C. L., \& Sherman, D. M. (1998). Intergenerational continuities and their influences on children's social development. Social Development, 7(3), 389427.

Reyna, V. F., \& Farley, F. (2006). Risk and rationality in adolescent decision making: Implications for theory, practice, and public policy. Psychological Science in the Public Interest, 7(1), 1-44.

Riaz, M. N., Riaz, M. A., \& Batool, N. (2012). Personality types as predictors of decision making styles. Journal of Behavioral Sciences, 22(2), 99-114.

Rinaldi, C. M., \& Howe, N. (2012). Mothers' and fathers' parenting styles and associations with toddlers' externalizing, internalizing, and adaptive behaviors. Early Childhood Research Quarterly, 27, 266-273.

Roche, K. M., Mekos, D., Alexander, D., Astone, N. M., BandeenRoche, K., \& Ensminger, M. E. (2005). Parenting influences on early sex initiation among adolescents: How neighborhood matters. Journal of Family Issues, 26, 32-54.
Roets, A., Schwartz, B., \& Guan, Y. (2012). The tyranny of choice: A cross-cultural investigation of maximizing-satisficing effects on well-being. Judgment and Decision Making, 7(6), 689704.

Roman, N. V., \& Davids, E. L. (2013). "To do or not to do": Examining decision making styles of university students in South Africa: Comparing family structure, gender and living arrangement. Journal of Community and Health Sciences, 8(2), $41-48$.

Roman, N. V., \& Frantz, J. M. (2013). The prevalence of intimate partner violence in the family: A systematic review of the implications for adolescents in Africa. Family Practice, 30(3), 256-266.

Roopnarine, J. L., Krishnakumar, A., Metindogan, A., \& Evans, M. (2006). Links between parenting styles, parent-child academic interaction, parent-school interaction, and early academic skills and social behaviors in young children of English-speaking Caribbean immigrants. Early Childhood Research Quarterly, 21, 238-252.

Saidur Rahaman, H. M. (2014). Personality and decision making styles of university students. Journal of the Indian Academy of Applied Psychology, 40(1), 138-144.

Salo, I., \& Allwood, C. M. (2011). Decision making styles, stress and gender among investigators. Policing: An International Journal of Police Strategies and Management, 34(1), 97-119.

Sari, E. (2008). The relations between decision making in social relationships and decision making styles. World Applied Sciences Journal, 3(3), 369-381.

Scott, S. G., \& Bruce, R. A. (1995). Decision making style: The development and assessment of a new measure. Educational and Psychological Measurement, 55, 818-831.

Shaffer, D. R., \& Kipp, K. (2014). Developmental psychology: Childhood and adolescence (9th ed.). Boston: Cengage Learning.

Simon, H. A. (1956). Rational choice and the structure of the environment. Psychological Review, 63, 129-138.

Smits, I., Soenens, B., Luyckx, K., Duriez, B., Berzonsky, M., \& Goossens, L. (2008). Perceived parenting dimensions and identity styles: Exploring the socialization of adolescents' processing of identity-relevant information. Journal of Adolescence, 31, 151-164.

Sorkhabi, N. (2005). Applicability of Baumrind's parent typology to collective cultures: Analysis of cultural explanations of parent socialization effects. International Journal of Behavioral Development, 29(6), 552-563.

Sovet, L., \& Metz, A. J. (2014). Parenting styles and career decision making among French and Korean adolescents. Journal of Vocational Behavior, 84, 345-355.

Steinberg, L. (2004). Risk taking in adolescence: What changes and why? Annals of the New York Academy of Sciences, 1021, 51-58.

Steinberg, L. (2007). Risk taking in adolescence: New perspectives from brain and behavioral science. Current Directions in Psychological Science, 16(2), 55-59.

Steinberg, L., Mounts, N., Lamborn, S., \& Dornbusch, S. (1991). Authoritative parenting and adolescent adjustment across various ecological niches. Journal of Research on Adolescence, 1, 19-36.

Supple, A. J., \& Small, S. A. (2006). The influence of parental support, knowledge, and authoritative parenting on Hmong and European American adolescent development. Journal of Family Issues, 27(9), 1214-1232.

Swartz, L., de la Rey, C., Duncan, N., \& Townsend, L. (2008). Psychology: An introduction. Cape Town: Oxford University Press.

Thomson, R. M., Allely, C. S., Purves, D., Puckering, C., McConnachie, A., Johnson, P. C. D., et al. (2014). Predictors of positive and negative parenting behaviors: Evidence from the ALSPAC cohort. BMC Pediatrics, 14, 247-257. 
Thunholm, P. (2004). Decision making style: Habit, style or both? Personality and Individual Differences, 36, 931-944.

Tinsley, H. E. A., Tinsley, D. J., \& Rushing, J. (2002). Psychological type, decision making style, and reactions to structured career interventions. Journal of Career Assessment, 10(2), 258-280.

Turner, S. L., Alliman-Brissett, A., Lapan, R. T., Udipi, S., \& Ergun, D. (2003). The career-related parent support scale. Measurement and Evaluation in Counseling and Development, 36, 83-92.

Udell, W., Bannon, W. M., \& McKay, M. M. (2008). Parenting practices and adolescent decision making: The importance of racial socialization. Social Work in Mental Health, 6(4), 65-79.

Vandeleur, C. L., Perrez, M., \& Schoebi, D. (2007). Associations between measures of emotion and familial dynamics in normative families with adolescents. Swiss Journal of Psychology, 66 (1), 5-16.

Vignoli, E., Croity-Belz, S., Chapeland, V., De Fillipis, A., \& Garcia, M. (2005). Career exploration in adolescents: The role of anxiety, attachment, and parenting style. Journal of Vocational Behavior, 67, 153-168.

Whittaker, K. A., \& Cornthwaite, S. (2000). Benefits for all: Outcomes from a positive parenting evaluation study. Clinical Effectiveness in Nursing, 4, 189-197.
Williams, U., \& Esmail, S. (2014). Association of different identity styles with sexual experience and decision-making among Canadian youth. Canadian Journal of Human Sexuality, 23(1), $49-58$.

Wolff, J. M., \& Crockett, L. J. (2011). The role of deliberative decision making, parenting and friends in adolescent risk behaviors. Journal of Youth and Adolescence, 40, 1607-1622.

Wong, W. C., Cheung, C. S., \& Hart, G. J. (2008). Development of a quality assessment tool for systematic reviews of observational studies (QATSO) of HIV prevalence in men having sex with men and associated risk behaviors. Emerging Themes in Epidemiology, 5, 23-27.

Wood, J. J., McLeod, B. D., Sigman, M., Hwang, W. C., \& Chu, B. C. (2003). Parenting and childhood anxiety: Theory, empirical findings, and future directions. Journal of Child Psychology and Psychiatry, 44, 134-151.

Yang, Z., Kim, C., Laroche, M., \& Lee, H. (2014). Parental style and consumer socialization among adolescents: A cross-cultural investigation. Journal of Business Research, 67, 228-236. 